\title{
EXPRESSION AND BIOINFORMATIC ANALYSIS OF THE ROP FAMILY GENE TaRAC IN WHEAT (TRITICUM AESTIVUM L.)
}

\author{
JiANG, Y. M. - YANG, J. W. - LIU, L. L. - LI, W. C. - ZhANG, B. Z. - YIN, J. - LI, L. * \\ National Engineering Research Center for Wheat, State Key Laboratory of Wheat and Maize \\ Crop Science, Collaborative Innovation Center of Henan Grain Crop, Henan Agricultural \\ University, Zhengzhou 450002, China \\ *Corresponding author \\ e-mail: nercw@126.com; phone: +86-135-9259-7894
}

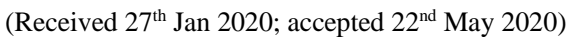

\begin{abstract}
The Ras related C3 botulinum toxin substrate (RAC) play a key role in dealing with abiotic stresses in plants. The full-length open reading frame of a TaRAC was firstly cloned from wheat. Bioinformatic analysis and expression profile analysis of the TaRAC gene were carried out. The results indicated that the full-length open reading frame of TaRAC was 594bp which encoded 197 amino acid residues. The genomic TaRAC gene had no introns. The protein encoded by the TaRAC gene consisted of a small GTPase Rho family domain profile. Blast and phylogenetic analysis showed that the protein encoded by TaRAC shared the identity with $R A C$ from corn (Zea mays L.). The result of qRT-PCR showed that expression of TaRAC gene was significantly tissue-specific. The result of qRT-PCR showed that TaRAC in the seeds was significantly higher than the expression of gene expression after soaking germination. The sensitivity of this gene to abscisic acid (ABA) significantly increased. TaRAC gene may play an important role in seed dormancy during germination, which could be used to improve the preharvest sprouting (PHS) resistance of wheat.
\end{abstract}

Keywords: wheat, preharvest sprouting, seed dormancy, abscisic acid, tissue-specific

\section{Introduction}

Preharvest sprouting (PHS) in wheat (Triticum aestivum L.) is the germination of grains in the ears when long range rainfall or damp conditions prior to harvest occur ( $\mathrm{Li}$ et al., 2019c). Small GTP binding proteins have a class of GTP binding proteins with molecular weight of 20-40 KD, including five families of Ras, Ran, Rab, Rho and Arf, which are involved in the regulation of eukaryotic cell proliferation, signal transduction and material transport (Takai et al., 2001; Kahn et al., 1992; Christensen et al., 2004). At present, more than 100 small GTP binding proteins have been found in eukaryotes, forming a huge superfamily.

There are many members in Rho subfamily. A group of small GTP binding proteins related to Rho subfamily were isolated by sequencing Arabidopsis genome. These proteins are evolutionarily independent and unique to plants. Because of their highest similarity with Ras related C3 botulinum toxin substrate (RAC) protein in animals, they are called RAC (Rho related GTPase from plant) or Rop protein family. The small GTP binding proteins of the Rop family have many functions, including the regulation of plant cell polarity, cell growth, morphological development, cytokinesis, hormone signaling, plant pathogen interaction, stress response and so on (Berken and Wittinghofer, 2008).

Several reports have suggested a function of RAC/ROPs as direct or indirect modulators of plant gene expression (Poraty-Gavra et al., 2013; Scheler et al., 2016). RHO GTPases were considered as transcriptional regulators because their downstream factors strongly affect gene expression and chromatin structure (Rajakyla and 
Vartiainen, 2014; Yu and Brown, 2015). It was found that a subset of plant Rac/Rop GTPases functions in mediating the auxin signal to downstream responsive genes basing on the tobacco overexpressing Rac/Rop GTPase, NtRac1 (Tao et al., 2002). Barley susceptibility factor RACB modulates transcript levels of signaling protein genes in compatible interaction with Blumeria graminis F. sp. hordei (Schnepf et al., 2018).

Transgenic crops can be used as powerful supplements to traditional breeding methods to meet the world's demand for high-quality food, and help combat malnutrition by improving yield, nutritional quality and resistance to various biological and abiotic stresses (Kamthan et al., 2016). RsRHA2b improves dormancy and preharvest sprouting tolerance in transgenic wheat (Bornman et al., 2019). Exogenous $R s R H A 2 b$ gene promoted the expression of YTH2456 (Li et al., 2019a). TaRHA2b interacts with TaRAC and other proteins ( $\mathrm{Li}$ et al., 2019b). Blast analysis of the YTH2456 show the sequence (AK251632.1) in barley and the RAC gene sequence (GU452718.1) in Wheat.

In order to make full use of the Rop family gene to improve the resistance to PHS in wheat, a Rop gene TaRAC was cloned from wheat by RT-PCR amplification. Bioinformatic analysis and expression profile analysis of the TaRAC gene with the treatment of different abscisic acid (ABA) concentration were carried out. The research could provide some reference for studying the mechanism of TaRAC gene in wheat dormancy, which may be used as an excellent gene resource to improve PHS resistance.

\section{Materials and methods}

\section{Meterials and $A B A$ treatment}

The wheat variety "Zhengmai 9023" was tested. The elite Chinese bread wheat cultivar Zhengmai 9023, a hexaploid wheat cultivar with weak resistance to PHS, which is widely cultivated in Henan Province.

\section{Extraction of total DNA and RNA and synthesis of cDNA first strand}

DNA was extracted from wheat germ with MiniBEST Plant Genomic DNA Extraction Kit. Trizol reagent was used to extract the total RNA from wheat germ. The extracted RNA was tested for quality and purity and then stored in a refrigerator at $80{ }^{\circ} \mathrm{C}$ for reserve. PrimeScript ${ }^{\mathrm{TM}} \mathrm{RT}$ reagent Kit (Perfect Real Time) was used to synthesize cDNA from total RNA. All operations are performed according to the instructions of the kits. The cDNA was stored at $-80{ }^{\circ} \mathrm{C}$ for later use.

\section{Cloning of TaRAC gene}

According to the amino acid sequence of the $R A C$ gene sequence (GU452718.1) in Wheat, specific Primer5.0 software was used to design the primers for the experiment (Table 1), and target gene prediction and in vitro splicing were conducted. The wheat cDNA was used as template for PCR amplification. PCR reaction system $20 \mu \mathrm{L}$ : 10x PCR Buffer $2.0 \mu \mathrm{L}, 2.5 \mathrm{mM}$ dNTPs $1.6 \mu \mathrm{L}, 10 \mathrm{pM}$ upstream and downstream primers each $0.8 \mu \mathrm{L}$, Taq enzyme ( $5 \mathrm{U} / \mu \mathrm{L}) 0.3 \mu \mathrm{L}$, cDNA template $1.0 \mu \mathrm{L}, \mathrm{ddH}_{2} \mathrm{O}$ complement $20 \mu \mathrm{L}$. Reaction conditions: $94{ }^{\circ} \mathrm{C}$ pre degeneration $3 \mathrm{~min} ; 94{ }^{\circ} \mathrm{C}$ modified $30 \mathrm{~s}, 50{ }^{\circ} \mathrm{C}$ annealing $40 \mathrm{~s}, 72{ }^{\circ} \mathrm{C}$ for $1 \mathrm{~min}, 30$ cycle; $72^{\circ} \mathrm{C}$ extension time for $10 \mathrm{~min}$.

The primer pairs $\mathrm{P} 1$ and $\mathrm{P} 2$ were designed according to the sequence of wheat TaRAC gene. The target sequence was obtained by RT-PCR amplification with primers 
P1 and P2. The PCR products were recovered and connected with the pGEMT vector, and the recombinant plasmid transformed into E. coli DH5 $\alpha$ competent cells, and the positive clones were screened and sent to BGI (HuaDa Biotechnology co., Itd., China) for sequencing.

Table 1. Primers sequences of the experiment

\begin{tabular}{c|c}
\hline Primers name & Primer sequence (from 5'sequence-3'sequence) \\
\hline P1 & ATGAGCGCTTCTCGGTTCAT \\
P2 & TTACAAAAAGGTGGATCCTT \\
P3 & GTTCCAATCTATGAGGGATACACGC \\
P4 & GTTCCAATCTATGAGGGATACACGC \\
P5 & CAGGTGGTCCGGCCGAGGTCGAT \\
P6 & CCAGGCACACGATGCACGTCGCCG \\
\hline
\end{tabular}

\section{Biological information analysis of TaRAC gene}

A comprehensive bioinformatics analysis was conducted using tools including the NCBI (https://www.ncbi.nlm.nih.gov/), Swiss-Prot databases (https://prosite.expasy.org/), DNAMAN and MEGA 7.0. Based on cDNA sequence, using NCBI site ORF Finder (https://www.ncbi.nlm.nih.gov/orffinder/) speculation TaRAC open reading frame. The consistency of TaRAC homologous genes with other species was analyzed using DNAMAN, and the evolution tree was constructed with the software MEGA 7.0.

\section{TaRAC gene expression analysis}

The root, stem, leaf, cob, lemma and endosperm from $25 \mathrm{~d}$ flowering wheat plants were taken. RNA was extracted, and reverse transcription was conducted to synthesize the first strand of cDNA. And PCR amplification was conducted with the first strand of cDNA as template. PCR reaction system $20 \mu \mathrm{L}$ : 10x PCR Buffer $2.0 \mu \mathrm{L}, 2.5 \mathrm{mM}$ dNTPs $1.6 \mu \mathrm{L}, 10 \mathrm{pM}$ upstream and downstream primers each $0.8 \mu \mathrm{L}$, Taq enzyme $(5 \mathrm{U} / \mu \mathrm{L}) 0.3 \mu \mathrm{L}$, cDNA template $1.0 \mu \mathrm{L}$, dd $\mathrm{d}_{2} \mathrm{O}$ complement $20 \mu \mathrm{L}$. Reaction conditions: $94{ }^{\circ} \mathrm{C}$ for $3 \mathrm{~min}, 94{ }^{\circ} \mathrm{C}$ for $30 \mathrm{~s}, 54{ }^{\circ} \mathrm{C}$ for $30 \mathrm{~s}, 72{ }^{\circ} \mathrm{C}$ for $40 \mathrm{~s}$, a total of 28 cycle, $72{ }^{\circ} \mathrm{C}$ extension time for $10 \mathrm{~min}$, electrophoresis detection of PCR products.

The Actin gene products amplified by wheat Actin gene specific primers were taken as internal reference. The primers of Actin gene used in PCR reaction were P3 and P4 (Table 1). And the primers of TaRAC gene were P5 and P6 (Table 1). According to the PCR reaction mixture system, PCR amplification conditions as follows: $94{ }^{\circ} \mathrm{C} 3 \mathrm{~min}$, $94{ }^{\circ} \mathrm{C}$ for $30 \mathrm{~s}, 54{ }^{\circ} \mathrm{C}$ for $30 \mathrm{~s}, 72{ }^{\circ} \mathrm{C}$ for $35 \mathrm{~s}$, a total of 28 cycle. $72{ }^{\circ} \mathrm{C}$ for $10 \mathrm{~min}$, RTPCR product after $1.0 \%$ agarose electrophoresis detecting camera, preservation. The experiment was repeated for three times.

Wheat seeds $(\mathrm{n}=150)$ with full and equal size after disinfection were soaked with ABA solution of $0.5 \mu \mathrm{M}$ (Li et al., 2019c), treatment without ABA was set for control, and samples were taken at different time (Table 2). RNA of dry seeds without soaking was extracted at the same time. PrimeScriptTM RT reagent Kit (Perfect Real Time) was used to synthesize cDNA from total RNA. The cDNA was numbered and stored at $80{ }^{\circ} \mathrm{C}$ for later use. 
Fluorescence quantitative PCR was used to analyze the TaRAC gene expression under ABA treatment with the primers P5 and P6 and internal reference Actin gene primers $\mathrm{P} 3$ and $\mathrm{P} 4$ (Table 1). According to the relative quantitative method to calculate: The relative expression of gene (Rel.Exp) $=2^{-\Delta \Delta \mathrm{Ct}}$, among them $-\Delta \Delta \mathrm{Ct}=$ Calibrator $\Delta \mathrm{Ct}-\Delta \mathrm{Ct}$ (the unknown sample), $\Delta \mathrm{Ct}$ (unknown sample) $=(\mathrm{Ct}$ ) internal gene - $(\mathrm{Ct})$ target gene, Calibrator $\Delta \mathrm{Ct}=(\mathrm{Ct})$ reference sample internal gene - $(\mathrm{Ct})$ reference sample target gene. The reaction system of fluorescence quantitative PCR was $20 \mu \mathrm{L}$ : SYBR Premix Ex TaqTM II, $10 \mu \mathrm{L}$, PCR Forward Premer $(10 \mu \mathrm{M}) 0.8 \mu \mathrm{L}$, PCR Reverse Premer $(10 \mu \mathrm{M}) 0.8 \mu \mathrm{L}$, ROX Reference Dye II (50x), cDNA template $2 \mu \mathrm{L}$, $\mathrm{ddH}_{2} \mathrm{O}$ up to $20 \mu \mathrm{L}$.

Table 2. Sampling time of the experiments with the treatment of $0.5 \mu M A B A$

\begin{tabular}{c|c}
\hline Group number & Sampling time (h) \\
\hline 1 & 0 \\
2 & 1 \\
3 & 2 \\
4 & 4 \\
5 & 8 \\
6 & 12 \\
\hline
\end{tabular}

\section{Statistical analysis}

The GraphPad Prism 8 was used for statistical analysis and drawing. For comparing results of different treatments, Variance analysis is followed by a post-hoc test in order to determine pairwise differences. Differences were considered significant for $\mathrm{P}<0.05$.

\section{Results}

\section{Sequence analysis of gDNA and cDNA of TaRAC gene}

It shows that the ORF region of TaRAC is 594 bp in length (Fig. 1). The obtained plasmid pGEM-T-TaRAC was sequenced. The results of sequences are listed in Figure 2. The sequencing results were matched with the accession number GU452718.1 after blast on NCBI, encoding 197 amino acid residues in an open reading frame with molecular weight of $21.662 \mathrm{kD}$ and isoelectric point of 9.26. The obtained pGEM-TTaRAC plasmids from cDNA and gDNA were sequenced and the results showed that there was no intron in the TaRAC gene in Figure 3.

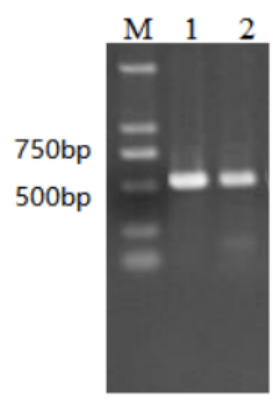

Figure 1. Sequence of the TaRAC gene. M, marker. 1 and 2, the target TaRAC fragment 
ATGAGCGCTT CTCGGTTCAT CAAGTGCGTG ACGGTGGGGG ACGGTGCCGT CGGCAAGACT TGCCTCCTCA TCTCCTACAC ATCCAACACC TTCCCCACCG ACTATGTCCC AACAGTCTTC GACAACTTCA GCGCTAACGT TGTGGTTGAC GGGAGCACCG TCAACCTCGG ATTATGGGAT ACTGCAGGAC AAGAGGACTA TAATAGACTA CGCCCACTGA GCTACCGAGG TGCCGATGTC TTCCTGCTCG CCTTTTCTCT TATCAGCAAA GCAAGCTACG AGAATGTCAC TAAGAAGTGG ATCCCTGAGC TACGGCACTA TGCTCCTGGT GTGCCCATAA TTCTTGTCGG GACAAAGCTT GATCTGCGGG ATGACCAGCA GTTTTTCGTG GATCACCCTG GGGCTGTTCC TATTTCCACC GCTCAGGGTG AAGAGCTGAA GAAGGTAATT GGCGCGACGG CCTACATCGA GTGCAGCTCA AAAACACAGC AGAACATCAA GGGGGGGTTT GATGGGGGAA TCAAGGGGTT TCTCCACCTT CCAAACCAGA AGCGGAAGAA GAGGAAGTCG CAAAAAGGAT CCACCTTTTT GTAA

Figure 2. The TaRAC fragment amplified by PCR
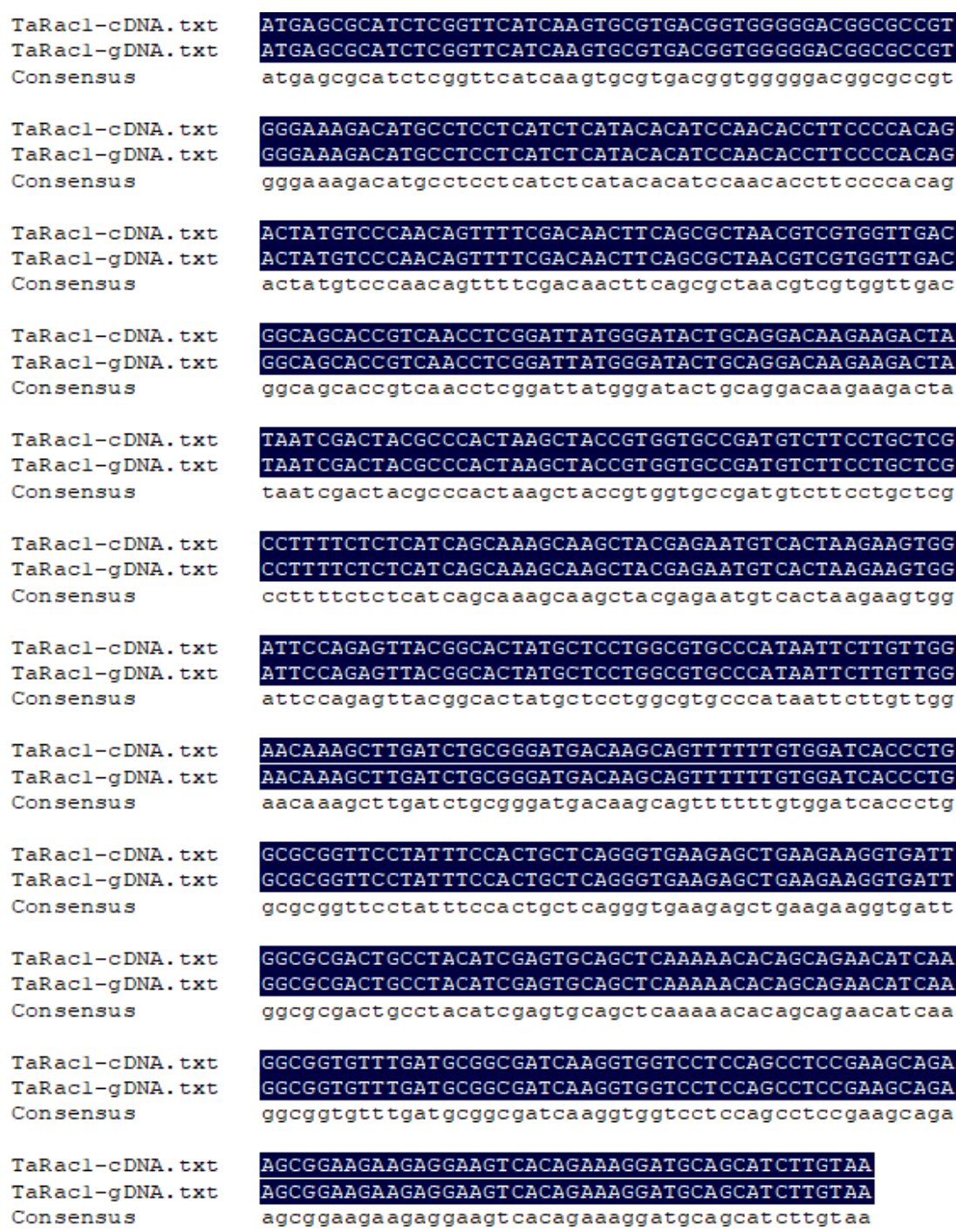

Figure 3. Comparative analysis between gDNA and cDNA sequences of TaRAC

\section{TaRAC encoding amino acid sequence alignment and phylogenetic tree}

After functional domain analysis of the encoded amino acids, it was found that there was a small GTPase Rho family profile, as shown in Figures 4 and 5. It contains a small 
GTPase Rho family domain. It is a polypeptide formed by 1-177 amino acids and belongs to an alkaline protein. TaRAC shared the identity with RAC from the corn.

\section{Expression analysis of the TaRAC gene}

The relative expression of TaRAC gene in different tissues (Fig. 6) showed that the specific expression bands of TaRAC gene could also be detected in the root, stem, leaf, cob, lemma and endosperm samples of wheat. The highest expression bands were found in leaves, cob, lemma and endosperm, and the signal intensity was significantly higher than that in roots and stems, which indicated that the transcriptional expression of TaRAC gene had strong tissue specificity.

\section{MSASRFIKCVTVGDGAVGKTCLLISYTSNTFPTDYVPTVFDNFSANVVVDGST VNLGLWDTAGQEDYNRLRPLSYRGADVFLLAFSLISKASYENVTKKWIPELR HYAPGVPIILVGTKLDLRDDKQFFVDHPGAVPISTAQGEELKKVIGATAYIECSS KTQQNIKAVFDAAIKVVLQPPKQKRKKRKSQKGCSIL}

USERSEQ1

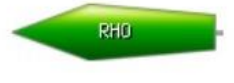

(197 aa)

Figure 4. Domain analysis of amino acids encoded by TaRAC gene. The yellow part of amino acid corresponds to the green part of the functional domain
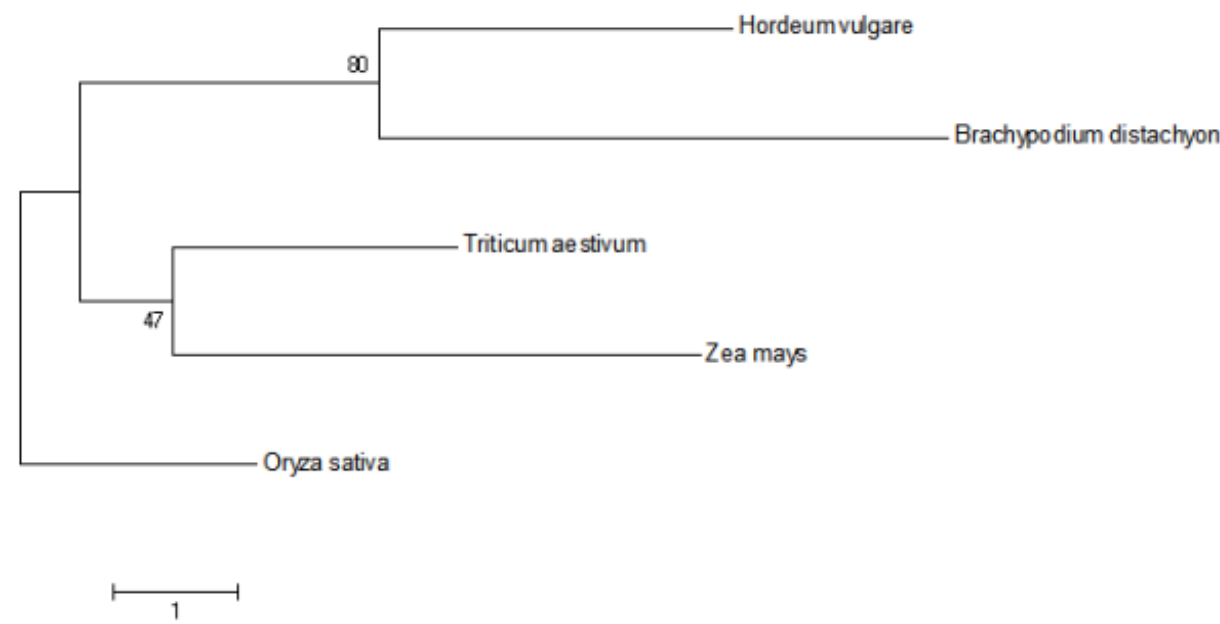

Figure 5. A phylogenetic tree of homology sequence with the TaRAC gene (with the software MEGA7.0). GU452718.1, Triticum aestivum, rac-type small GTP-binding protein mRNA; AK251632.1, Hordeum vulgare; XM_003570698.4, Brachypodium distachyon, rac-like GTPbinding protein 5 mRNA; EU968843.1, Zea mays clone 324497, rac-like GTP-binding protein 5 mRNA; AF218381.1, Oryza sativa, subsp. japonica small GTP binding protein RACP (RAC) mRNA 


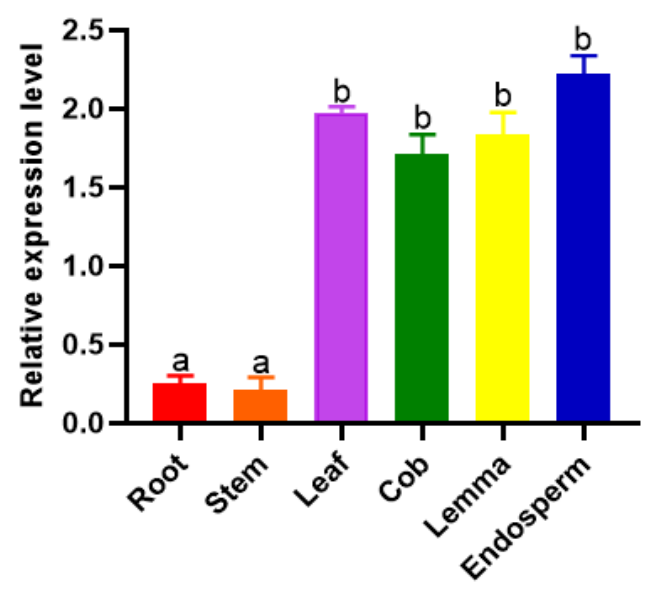

Figure 6. Expression analysis of TaRAC gene in different tissues of wheat. The letters ' $a$ ' to ' $b$ ' indicate statistically significant differences $P<0.05$ (Tukey's least significantly difference test).

Data are expressed as mean values standard errors from three replicates and error bars represent standard errors

\section{TaRAC gene expression is sensitive to exogenous $A B A$ treatment}

Different concentrations of ABA were used to treat wheat seedlings at two-leaf stage. Real-time fluorescence quantitative PCR (RT-PCR) amplification was performed with primers to analyze the response of TaRAC gene to ABA in early germination seedlings. Quantitative fluorescence assay (Fig. 7) showed that under $5 \mathrm{~mol} / \mathrm{L} \mathrm{ABA}$ treatment, the expression of TaRAC gene peaked at $8 \mathrm{~h}$, and the response was obvious. The results showed that TaRAC gene was sensitive to the change of ABA concentration. Within a certain ABA concentration range, the response time of TaRAC gene would be shortened, but when beyond a specific ABA concentration range, the response of TaRAC gene was passivated.

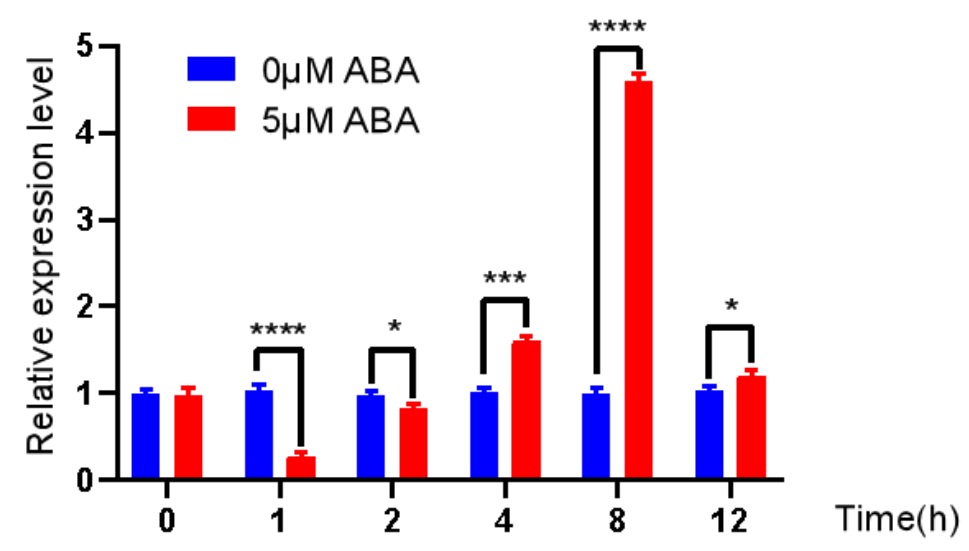

Figure 7. Relative expression levels of TaRAC gene at different times with $0 \mu M$ and $5 \mu M A B A$ treatment. The symbol '*' indicates statistically differences $P<0.05$, the symbol '**' indicates statistically differences $P<0.01$; the symbol '***'indicates statistically differences $P<0.001$; the symbol '****' indicates statistically differences $P<0.0001$ (Turkey's least significantly difference test). Data are expressed as mean values standard errors from three replicates and error bars represent standard errors 


\section{Discussion}

Plant RAC/ROP proteins are involved in a series of important biological processes, such as plant polar growth, hormone signal transduction, plant disease resistance and abiotic stress resistance, by regulating the assembly of cytoskeleton actin, the production of reactive oxygen species and the change of $\mathrm{Ca}^{2+}$ concentration in cells (Zheng and Yang, 2000; Li et al., 2001). RAC1 was cloned from pea for the first time and found to be related to the growth of pea pollen tube (Yang and Watson, 1993). RAC protein was involved in the polar growth of pollen tube and root hair cells (Ye et al., 2003; Lee and Yang, 2008; Hwang et al., 2010).

The expression of TaRAC in different tissues of wheat was detected by qRT-PCR. The results showed that the gene had different abundances in different tissues of wheat, with certain tissue specificity, and the highest expression in leaves, cob, lemma and endosperm.

RAC/ROP protein was also involved in plant hormone signal transduction. For example, auxin related genes were also induced in tobacco and corresponding active mutants that overexpress NTRacl (Morel et al., 2004). Exogenous ABA can inhibit the expression of AtRop10 in Arabidopsis, while the deletion mutant of this gene is more sensitive to ABA (Zheng et al., 2002). RAC/ROP protein was also involved in the response of plants to abiotic stress, and the salt resistance of Arabidopsis plants overexpressing tobacco NtRopl was improved (Cao et al., 2010). Arabidopsis AtRop6 and AtRopl1 enhanced drought resistance of plants through stomatal closure regulated by ABA (Lemichez and E., 2001; Zheng et al., 2002).

Plant RAC/ROP protein genes are involved in many plant stress responses. TaRAC can promote ABA induced responses, such as seed germination, root elongation, stomatal closure, and $\mathrm{ABA}$ can also play a negative role in regulating TaRAC. In the present study, the TaRAC gene of wheat was cloned, and its molecular structure, tissue expression specificity and expression under ABA treatment were analyzed. It is suggested that the gene may be involved in wheat development, especially in response to abiotic stress, which provides a theoretical basis for further study of the role of TaRAC protein in plant resistance to spike germination.

ABA signaling pathway is closely related to plant stress resistance. In the present study, exogenous ABA promoted the expression of TaRAC gene. It is suggested that the increase of TaRAC gene expression may promote the cascade amplification of ABA signal transduction and improve plant resistance.

The expression profile of TaRAC gene with the treatment of different ABA concentration showed that TaRAC gene was highly expressed in seedlings. The results indicated that the function of $R A C$ gene in plants is related with $\mathrm{ABA}$ signal transduction pathway. The results showed that TaRAC gene may be an excellent genetic resource to improve PHS resistance.

Rac GTPases play an important role in the regulation of secondary metabolism in plant cells and that overexpression of the gene(s) may be capable of enhancing the production of natural products accumulated in higher plant cells (Asano et al., 2013). The expression profile of TaRAC gene and the main functional domain of the protein encoded by a gene were analyzed to reveal that the gene may be involved in the regulation of wheat resistance to PHS. More work is needed for using TaRAC gene to improve dormancy and PHS tolerance in wheat. 


\section{Conclusion}

The full-length ORF of the TaRAC gene was cloned from wheat. The full-length ORF of TaRAC encoded 197 amino acid residues, which was consisted of a small GTPase Rho family profile. The genomic TaRAC gene had no introns. TaRAC shared the identity with RAC from the corn. The expression of TaRAC gene was significantly tissue-specific. The expression of TaRAC in the seeds was significantly higher than the expression of gene expression after soaking germination. The sensitivity of the TaRAC gene to ABA was significantly increased. In the next step, we will use transgenic wheat lines to further clarify the function, subcellular localization of TaRAC gene and its role in $\mathrm{ABA}$ mediated signal transduction pathway, providing effective candidate genes for wheat resistance to PHS and stress breeding.

Acknowledgements. This work was supported by the National key R \& D Projects (2017YFD0301101).

Conflict of interests. The authors state no conflict of interest.

\section{REFERENCES}

[1] Asano, K., Lee, J., Yamamura, Y., Kurosaki, F. (2013): Enhanced accumulation of atropine in Atropa belladonna transformed by Rac GTPase gene isolated from Scoparia dulcis. - Transgenic Research 22: 1249-1255.

[2] Berken, A., Wittinghofer, A. (2008): Structure and function of Rho-type molecular switches in plants. - Plant Physiology and Biochemistry 46: 380-393.

[3] Bornman, J. F., Barnes, P., Robson, T. M., Robinson, S. A., Jansen, M. a. K., Ballare, C. L., Flint, S. D. (2019): Linkages between stratospheric ozone, UV radiation and climate change and their implications for terrestrial ecosystems. - Photochemical and Photobiological Sciences 18: 681-716.

[4] Cao, Y. R., Zhigang, L. I., Tao, C., Zhang, Z. G., Zhang, J. S., Chen, S. Y. (2010): Overexpression of a tobacco small G protein gene NtRop1 causes salt sensitivity and hydrogen peroxide production in transgenic plants. - Phytochemical Analysis 13: 189194.

[5] Christensen, T., Vejlupkova, Z., Sharma, Y., Arthur, K., Spatafora, J., Albright, C., Meeley, R., Duvick, J., Quatrano, R., Fowler, J. (2004): Conserved subgroups and developmental regulation in the monocot rop gene family. - Plant Physiology 133: 17911808.

[6] Hwang, J., Wu, G., Yan, A., Lee, Y., Grierson, C. S., Yang, Z. (2010): Pollen-tube tip growth requires a balance of lateral propagation and global inhibition of Rho-family GTPase activity. - Journal of Cell Science 123: 340-350.

[7] Kahn, R., Der, C., Bokoch, G. (1992): The RAS superfamily of GTP-binding proteins: guidelines on nomenclature. - FASEB Journal 6: 2512-2513.

[8] Kamthan, A., Chaudhuri, A., Kamthan, M., Datta, A. (2016): Genetically modified (GM) crops: milestones and new advances in crop improvement. - Theoretical and Applied Genetics 129: 1639-1655.

[9] Lee, Y. J., Yang, Z. (2008): Tip growth: signaling in the apical dome. - Current Opinion in Plant Biology 11: 662-671.

[10] Lemichez, E. (2001): Inactivation of AtRac1 by abscisic acid is essential for stomatal closure. - Genes \& Development 15: 1808-1816.

[11] Li, D., Lyu, G., Jiang, Y., Niu, H., Wang, X., Jun, Y. (2019a): Effects of exogenous $R s R H A 2 b$ gene on key enzyme activities and expression of related genes in grain filling 
stage of wheat (Triticum aestivum L.). - Applied Ecology and Environmental Research 17: 15073-15086.

[12] Li, D., Lyu, G., Jiang, Y., Niu, H., Wang, X., Jun, Y. (2019b): Interaction network of TaRHA2b of wheat (Triticum aestivum L.) based on high-throughput yeast two-hybrid screening. - Applied Ecology and Environmental Research 17: 13105-13124.

[13] Li, D., Lyu, G., Lyu, J., Niu, H., Wang, X., Jun, Y. (2019c): Cloning and characterization of a wheat RING finger gene TaRHA2b whose expression is up-regulated by ABA treatment. - Applied Ecology and Environmental Research 17: 7495-7510.

[14] Li, H., Shen, J., Zheng, Z., Lin, Y., Yang, Z. (2001): The Rop GTPase switch controls multiple developmental processes in Arabidopsis. - Plant Physiology 126: 670-684.

[15] Morel, J., Fromentin, J., Blein, J., Simonplas, F., Elmayan, T. (2004): Rac regulation of NtrbohD, the oxidase responsible for the oxidative burst in elicited tobacco cell. - Plant Journal 37: 282-293.

[16] Poraty-Gavra, L., Zimmermann, P., Haigis, S., Bednarek, P., Hazak, O., Stelmakh, O. R., Sadot, E., Schulze-Lefert, P., Gruissem, W., Yalovsky, S. (2013): The Arabidopsis Rho of plants GTPase AtROP6 functions in developmental and pathogen response pathways. - Plant Physiology 161: 1172-1188.

[17] Rajakyla, E. K., Vartiainen, M. K. (2014): Rho, nuclear actin, and actin-binding proteins in the regulation of transcription and gene expression. - Small GTPases 5: 1-14.

[18] Scheler, B., Schnepf, V., Galgenmuller, C., Ranf, S., Huckelhoven, R. (2016): Barley disease susceptibility factor RACB acts in epidermal cell polarity and positioning of the nucleus. - Journal of Experimental Botany 67: 3263-3275.

[19] Schnepf, V., Vlot, A. C., Kugler, K. G., Huckelhoven, R. (2018): Barley susceptibility factor RACB modulates transcript levels of signalling protein genes in compatible interaction with Blumeria graminis F. sp. hordei. - Molecular Plant Pathology 19: 393404.

[20] Takai, Y., Sasaki, T., Matozaki, T. (2001): Small GTP-binding proteins. - Physiological Reviews 81: 153-208.

[21] Tao, L., Cheung, A. Y., Wu, H. (2002): Plant Rac-like GTPases are activated by auxin and mediate auxin-responsive gene expression. - The Plant Cell 14: 2745-2760.

[22] Yang, Z., Watson, J. C. (1993): Molecular cloning and characterization of Rho, a Rasrelated small GTP - binding protein from the garden pea. - Proceedings of the National Academy of Sciences of the United States of America 90: 8732-8736.

[23] Ye, J., Huang, M., Wu, N. (2003): Fertility analysis of the Arabidopsis transformed with antisense rice osRACD gene. - Progress in Natural Science 13: 424-428.

[24] Yu, O. M., Brown, J. H. (2015): G Protein-coupled receptor and RhoA-stimulated transcriptional responses: links to inflammation, differentiation, and cell proliferation. Molecular Pharmacology 88: 171-180.

[25] Zheng, Z. L., Yang, Z. (2000): The ROP GTPase: an emerging signaling switch in plants. - Plant Molecular Biology 44: 1-9.

[26] Zheng, Z. L., Nafisi, M., Tam, A., Li, H., Crowell, D. N., Chary, S. N., Schroeder, J. I., Shen, J., Yang, Z. (2002): Plasma membrane-associated ROP10 small GTPase is a specific negative regulator of abscisic acid responses in Arabidopsis. - Plant Cell 14: 2787-2797. 